\title{
Study of antioxidant, anticoagulation and antiaggregational activity in vitro of a number of aliphatic and aromatic amino acid salts
}

\author{
C Natalia A. Bondareva, ${ }^{+}$Peotr P. Purygin, ${ }^{*}$ Yury P. Zarubin, and Alexandr V. Samorodov \\ Department of Inorganic Chemistry. Samara University. Moskovskoye Shosse, 34. Samara, 443086. \\ Volga Federal District. Samara Region. Russia.Phone: +7 (846) 334-54-59.E-mail: nnkk86@mail.ru
}

*Supervising author; ${ }^{+}$Corresponding author

Keywords: amino acids, amino acid salts, hemostasis, antioxidants, aliphatic amino acids, anticoagulants, antiplatelet agents, in vitro.

\section{Abstract}

Among the nitrogen-containing organic substances there are compounds with a dual function. Particularly important are amino acids. Strictly speaking, amino acids make up only one of the many families of organic compounds. Any organic molecule having at least one amino and one acid group may be assigned to this family. This generally means any hydrocarbon chain that may be branched, with or without other functional groups, aromatic rings, or any other organic structure. Therefore, it becomes clear that the number of amino acids that can be imagined is infinite.

Today in Russia there is a huge need to develop new and effective drugs for the treatment of various diseases. This important task involves organizing the production of new competitive domestic medicines on the market, the development of which is carried out on the basis of the results of fundamental scientific research in the field of organic synthesis.

In this regard, derivatives and salts of amino acids are of great interest, due to their high reactivity and wide use in medical practice.

We have studied the effect on the hemostasis system of derivatives based on amino acid salts, which is currently a key task of organic, bioorganic and medicinal chemistry. Consideration of the scientific literature on this topic showed the saturation and increasing interest in the influence of amino acid compounds throughout the world.

The synthesis of amino acid salts and the study of their effect on the blood curability system was carried out, optimal synthesis methods for an organic compound were developed. Preliminary in vitro preclinical studies of the obtained compounds were carried out in order to find out the prospects for their further use.

\section{References}

[1] N.A. Bondareva, P.P. Purygin, and O.O. Isaeva. Synthesis and biological activity of a number of salicylic acid esters. Butlerov Communications. 2019. Vol.60. No.11. P.93-97. DOI: 10.37952/ROI-jbc-01/19-60-11-93

[2] A.A. Zheltova Pharmacological correction of endothelial dysfunction and myocardial ischemia in conditions of experimental magnesium deficiency: Abstract of PhD Thesis. 2012. (russian)

[3] Yu.Yu. Sevryugina Synthesis and analysis of some derivatives of glutamic acid: Abstract of PhD Thesis. Moscow. 1994. P.123-126. (russian)

[4] S.N. Luneva, A.M. Nakoskin, L.A. Vaganova. Metabolism of rat bone tissue after oral administration of calcium amino acid complexes. Scientific and Innovative Journal Trans-Ural Scientific Bulletin."2012. Iss.2. P.79-83. (russian)

[5] Guidelines for conducting preclinical studies of drugs. Part one. Moscow: Grif and K. 2012. 944p. (russian)

[6] BORN, G. Aggregation of Blood Platelets by Adenosine Diphosphate and its Reversal. Nature. №194. P.927-929 (1962). https://doi.org/10.1038/194927b0. 